\title{
Imagining the other? Ethical challenges of researching and writing women's embodied lives
}

Carla Rice

Trent University

This is an Accepted Manuscript of an article published by Sage Journals in Feminism \& Psychology on May 1, 2009, available online:

https://journals.sagepub.com/doi/10.1177/0959353509102222.

Recommended citation:

Rice, C. (2009). Imagining the other? Ethical challenges of researching and writing women's embodied lives. Feminism \& Psychology, 19(2): 245-266. https://doi.org/10.1177\%2F0959353509102222 


\section{Imagining the Other? Ethical Challenges of Researching and Writing Women's Embodied Lives}

Carla Rice

ABSTRACT

Feminists influenced by post-conventional and critical perspectives confront a significant challenge when researching women's embodiments: the dilemma of representation. For researchers from positions of bodily privilege, issues of interpretation intensify when researching and writing across physical differences distorted by colonial and other hegemonic histories and legacies. In this article, I draw from interviews with diversely embodied women to discuss difficulties encountered in interpreting their narratives of embodiment. I reflect on strategies of embodied engagement, including de-centring my bodily self, re-visiting my body story, and imagining the other's embodied experiences in the creation of provisional meanings about participants' bodies and lives. To shed light on risks and rewards of researcherembodied reflexivity to study sensitive subjects such as appearance and difference, I show how analysing my 'body secrets' invites deeper exploration into dynamics of bodily privilege and abjection underpinning women's accounts. I conclude by questioning the ethics of my 'imaginative leap' into other/ed women's lives and by considering more broadly the perils and possibilities of traversing the space between self and other, and other in the self, within feminist research.

Key Words:

body image, body secrets, embodied engagement, interviewing, interpretation, physical difference, researcher reflexivity

... imagining is not merely looking or looking at; nor is it taking one's self intact into the other. It is, for the purposes of the work, becoming. 
(Toni Morrison, 1992: 4)

Researchers guided by feminist and postmodern theory identify three interrelated dilemmas associated with doing qualitative research: ethics, power and difference (Wolf, 1996). Approaching ethics as a process of critical reflection, many feminist researchers strive to establish egalitarian relationships and encourage participants' involvement in interpretation of their lives (Canadian Research Institute for the Advancement of Women (CRIAW), 1996). Feminists express commitment to critical analysis and responsible use of power in interviewing and interpretation, yet also discuss the potential for manipulation, misunderstanding and misrepresentation of participants (Fonow and Cook, 2005). To interrogate implications of differences, some advocate 'strong reflexivity' that attends to diversity of informants and explicates the ways that differences between researchers and respondents shape research processes (McCorkel and Myers, 2003: 203). Those concerned about the colonizing implications of focusing solely on 'others' recently have turned the gaze on themselves to analyse how conundrums of ethics, power and difference converge on questions of subjectivity (Ghorashi, 2005; Henry, 2003). As feminist poststructuralists have shown, subjectivity, rather than being fixed, contained or beyond the body, is an embodied, multifaceted and fluid experience of the self that is shaped by, and shapes, the social world (Shildrick, 1997). Because subjectivities are neither disembodied nor detached, researchers' personal histories, physicalities and positionalities necessarily inform the theoretical stories they tell. When emotion, perception, imagination and other dimensions of the bodily self are the main instruments of data creation, dilemmas of researchers' embodied subjectivities are not resolved but become central ethical considerations in research.

In this article, I examine a central methodological conundrum informed by feminist critiques of conventional research methods. Reflecting on a research project investigating women's body histories, I ask: how can critical researchers cultivate ethical relationships that incorporate our subjectivities yet refrain from centring our experiences or irresponsibly interpreting those of participants? When studying sensitive subject matters such as body image where issues of appearance cannot be 
overlooked, how do we account for the influence of our physicalities? How can critical reflections on our own embodied subjectivities carefully and cautiously be employed to enrich the analyses and further feminist critical concerns? What are the implications for research activities and outcomes of remaining silent about our personal histories, physical embodiments and points of experiential commonality or difference with participants?

To explore such tensions, I critically consider the significance of my body history during a qualitative research project I undertook to understand women's diverse experiences of their bodies across the life span. I reflect on strategies of 'embodied engagement', such as de-centring my bodily self, revisiting my body story and imagining the other, in the creation of provisional meanings about participants' bodies and lives. To shed light on challenges of 'embodied reflectivity' (Burns, 2006: 3), I analyse what I chose to conceal and reveal about my bodily experiences in conversations with contributors and academic audiences. Through interrogating my 'body secrets', I theorize ways that bodily privilege and abjection mark my interpretation of informants' accounts. While researchers' and participants' physicalities often are overlooked in discussions of reflexivity, I suggest that where appearance and bodily difference surface as pivotal social categories, as they do in embodiment research, these ought not to be ignored or subsumed under more accepted analytic categories such as gender, race or class. I conclude by questioning the ethics of my own 'imaginative leap' into other/ed women's lives and by considering more broadly the possibilities and perils of traversing the space between self and other, and 'other in the self', within feminist research.

HISTORY OF THE PROJECT: BECOMING WOMEN THROUGH THE BODY

I became interested in women's body image formation as a result of my 20 years' experience as an activist and clinician working with body image struggles. My impetus to investigate diverse women's embodiments was also propelled by painful personal experiences of growing up in a body that was perceived as deficiently different. Drawing on feminist poststructuralist perspectives, I understood 'body images' as women's perceptions of appearance and difference configured through 
social representations and relations, including inter-corporeal exchanges within which they envisioned, and revisioned, their sense of bodily self (Wiess, 1999). By researching 'embodiments', I wanted to reveal bodily experiences con- stitutive of subjectivity that were produced, perceived and lived through meaning systems circulating within women's everyday social lives (Zitzelsberger, 2005). In consumerist, modernist and media-driven cultures where women are socially identified with their bodies, I held that meanings given to informants' bodies would become a vital basis for identities.

Because most body image research focuses on white, middle-class, averagesized and non-disabled women's weight problems, I decided to interview diversely embodied women to learn more about affinities and differences in their body experiences. The research asked: How do women negotiate cultural meanings given to bodies and use these interpretations to shape their identities, subjectivities and sense of life possibilities? The study traced the role of the body in women's identity acquisition in the timeframe from early childhood to late adolescence. It followed their creation of body images and initiation into body alteration as attempts to give symbolic and material form to received and preferred accounts of themselves. To ensure inclusion of diverse voices and vantage points, I combined snowball and strategic sampling (Strauss and Corbin, 1998), and conducted 81 in-depth, openended, semi-structured interviews that ran from 120 to 240 minutes over one, two or three sessions. These narratives were told by women between the ages of 20 and 45 , of varying sizes, from different social classes, diverse racial backgrounds, and with and without disabilities and physical differences. 1 Included were participants

\footnotetext{
1 Participants in this study equally comprised racialized and non-racialized women, including Northern European (28\%), African-Caribbean (20\%), South Asian (14\%), Southern/Eastern European (13\%), and Asian (10\%) Canadian women. Mobility and sensory disabilities of participants included cerebral palsy and blindness (11\%); their facial and physical differences consisted of craniofacial conditions and scoliosis (9\%); and their chronic illness ranged from rheumatoid arthritis to reproductive disorders (23\%). While women evenly described growing up in middle- $(43 \%)$ and working- or welfare-class households $(40 \%)$, at the time of the interview a majority $(61 \%)$ reported their income situation was 'limited' (under $\$ 30,000)$. Most $(90 \%)$ described how they came to see themselves as over- or underweight and $25 \%$ formed a 'fat' identity by the end of adolescence. These statistics provide a partial snapshot of participants' identities, yet conventional labels also collapse multifaceted differences into predefined
} 
perceived as conventionally attractive as well as those deemed different because of fat, unusual, uncontrollable, absent or other rejected body parts and processes rendered as 'abject' in our culture (Kristeva, 1982).

Inspired by such a diverse sample of interviewees, I searched for interpretive approaches that would help me compose a credible theoretical story. Constant comparative coding (Strauss and Corbin, 1998) permitted insights into commonalities across differences by emphasizing micro-level interactions that participants repeatedly identified as privileged sources of cultural knowledge regarding their bodies. Luttrell likewise makes a good case for finding patterns across rather than within individuals' narratives. She tells how through coding, she 'lost the capacity to see each woman primarily as an individual with her own story to tell', but gained clarity on 'links between the social and the psychological in the women's narratives' (2000: 508). Yet as this process progressed, I observed that because coding fragmented individuals' accounts, it was not helpful for analysing complex effects of meanings conveyed in interactions or for understanding how participants used such messages to shape their sense of bodily self. To preserve coherency and complexity of accounts and privilege women's ways of interpreting embodied experiences, I turned to narrative inquiry (Clandinin and Connelly, 2000) as my second interpretive lens.

From a poststructuralist feminist vantage point, the narratives people compose from personal experiences, informed by broader cultural scripts, contribute to their construction of identities and selves (Reissman and Quinney, 2005). Rather than approaching the accounts as accurate representations of reality or imagined texts of fiction, I came to view women's versions as stories they made to give meaning to their experiences, and later modified to connect and communicate with others. After analysing data inductively to formulate themes that explained the role of the body in identity formation, I moved to capture deductively through narrative analysis complexities, intentions and agency embedded in women's accounts. Empiricist

categories. Complex, contradictory and changing meanings of differences given in interactions had implications for women's bodies and lives that were not easily predicted by conventional groupings. To capture their multiple and shifting identities, I also kept women's descriptions intact. 
approaches of coding combined with poststructuralist narrative analysis shed light on social processes underpinning personal accounts, while illuminating women's abilities to craft and maintain a sense of self in the context of disparaging images and daily intrusions. By interweaving individuals' insights with social analysis, I aimed to 'hold an analytic perspective while remaining empathically attuned to the ways participants [made] sense of their lives' (Hoskins and Stoltz, 2005: 99).

Drawing on feminist poststructuralist methodology (Naples, 2003), my approach to analysing data evolved to encompass four guiding principles: (1) use of a hybrid 'inductive-deductive' approach to integrate grounded theory methodologies with poststructural narrative interpretation; (2) emphasis on contradiction, complexity and theoretical plurality; (3) privileging of participants' experiential knowledges, agency and creativity; and (4) attending to experiences of difference throughout interviewing and theorizing. Through this process, feminist postmodern theories of the body (Grosz, 1994), subjectivity (Shildrick, 1997), identity (Mama, 1995) and difference (Brah, 2001) emerged as pivotal to building theoretical understanding from women's experiential knowledges. As interpretation advanced, I realized that regardless of analytic approaches taken, risks of misrecognition and misrepresentation intensified for white, western, average- sized and non-disabled feminists such as myself while researching across differences distorted by inequities in symbolic and social relations (Tuhiwai Smith, 1999). With this apprehension, I returned once again to postmodern methodologies to consider how dilemmas of bodily difference and subjectivity infused data collection and interpretation. The aim of this article is to subject my physicality and subjectivity to close scrutiny to examine how researcher reflexivity resolved or left unresolved ethical challenges throughout this research. In order to do so, a brief overview of some key feminist methodological dialogues and dilemmas is first warranted.

\section{DIALOGUES AND DILEMMAS IN FEMINIST RESEARCH}

Feminist methodology developed as a critical response to more conventional forms of research that were seen to carry substantial risks for exploitative treatment of participants. For example, traditional social research often devalued participants' 
personal stories and understandings of their lives. Significant power differentials between researcher and researched were ignored or seen as inconsequential to research activities and outcomes. The social science researcher was viewed as an objective, disembodied voice, without any particular vantage point or values, who simply studied 'others' - often socially marginalized groups - and unearthed the 'truth' about their lives (Oakley, 1981). While the challenges of this legacy remain, many theorists have envisioned more self-conscious, account- able and collaborative ways of relating to participants, collecting data, analysing results and representing others' stories (Fonow and Cook, 2005). These methods, too, call for reflexivity and revision.

Investigators informed by feminist methodology have often maintained that it is important to use individuals' stories as a basis for theorizing. At the same time, many methodologists have acknowledged the limitation in assuming 'transparency' of narratives and the likelihood that power dynamics will influence data compilation. To address the latter, some feminists argue for establishing reciprocal relationships with informants. For example, in her classic critique of conventional social science research, Oakley (1981) unmasks power relations underlying assumed neutrality of mainstream methods to argue for more relational approaches such as sharing similar stories, offering affirming commentary and forging friendships with informants. More recently, feminists have maintained that this romanticized view of reciprocity ignores power dynamics between women differently positioned in research relationships and disregards the dominant part played by researchers in shaping study findings (McCorkel and Myers, 2003).

To declare their own role in data collection and interpretation, many feminists advocate making transparent the investigator's gaze by practising disclosure of their identities to place themselves on the same 'critical plane' as participants (Bloom, 1998). In this present study, this has meant my making explicit significant identities that have influenced interactions with informants: for example, I am a white, Canadian-born woman with a working-class background, as well as a lesbian in a biracial relationship. When conducting research on sensitive subjects such as appearance and physical difference, others advocate making visible aspects of 
researchers' and respondents' embodiments that may have affected encounters (Burns, 2006): for instance, that I am a woman in my early 40s who fits certain standards of attractiveness and who enjoys the clothes, makeup and other visual expressions of conventional femininity. Yet because such descriptions tend to encourage centring of researchers' embodied subjectivities and skirting of power dynamics underpinning data production, others caution that this approach may privilege researcher perspectives over participant realities (Wolf, 1996). In advocating 'strong reflexivity' (McCorkel and Myers, 2003), some researchers hope to move beyond simple acknowledgement of social identities to interrogate complex effects of differences on data produced, without centring or suppressing their subjectivities in the process.

The central aim of such self-conscious de-centring is to create opportunities for marginalized communities to tell their stories. Still, feminists acknowledge the potential for abuse inherent in reconstructing accounts of other/ed women's lives. To mitigate potential for missing participants' meanings and to come closer to their worlds, feminists advocate a range of ethical practices. These include: researcher accountability through checking interpretations with informants and consequences of representations for researched groups (Cosgrove and McHugh, 2000); researcher responsibility through immersing oneself in experiences, worldviews and challenges of communities under investigation (Merrick, 1999); researcher advocacy through commitment to producing knowledge with possibilities for improving marginalized people's lives (Fine et al., 2003); and researcher reflexivity through interrogating researcher emotions, embodiments, identities and allegiances that affect research processes (Johnson-Bailey, 1999; Reger, 2001).

Throughout my project, these tenets of feminist research have acted as important guiding principles. For example, rather than writing one 'true' theoretical story, I aimed to craft respectful and responsible representations by navigating my interpretative insights, participant knowledges, feminist embodiment theory and audience responses to early efforts at interpretation. Yet I also have struggled with many of their inherent contradictions, most notably with self-reflexivity. To shed light 
on why dilemmas of self-disclosure have been so difficult, in what follows, I examine how secrets in my own body story complicated and, at the same time, provided important entry points into interpretation of participants' accounts.

\section{CONUNDRUMS OF BODY SECRETS: THE 'ELEPHANT IN THE ROOM'}

My own account of my relationship to this research topic is heavy with secrets and silence. I am a former fat girl. This embodied identity haunts me up to the present day. As the research project progressed, my body shifted from a comparatively large to a culturally acceptable size. This weight loss began with an illness, and continued as a result of my own intentionality. After experiencing the privileges associated with attaining a gendered size norm and in order to stave off the violating comments that were common features of life as a fat woman, I adopted strict disciplinary practices of eating and exercise that have 'worked' with considerable effort on my part. Although I lost weight gradually over a long period of time, today as I move through space I imagine my bodily boundaries to be much larger. For example, I still feel a familiar unpleasant shot of anxiety in environments and technologies built for average bodies: will I be able to fit into a subway, bus or airplane seat without evoking other passengers' irritation or anger for taking up too much space? Or risk humiliating or hostile looks and comments if I expose my fat flesh in a public place?

The body secrets do not stop at my former fat girl identity. I also am a woman with facial hair. This aspect of my embodied identity I have hidden through electrolysis and other efforts at hair removal. As with fat, anxieties about exposing this devalued difference today continue to plague me: will unmasking my abject hair and its removal invite others' pitiful or critical gaze? Or increase my vulnerability to harsh assessments that I have 'failed' as a feminine, or as a feminist, woman?

Throughout interviewing and interpretation, and during public talks on the research, I have repeatedly confronted situations in which others' and my own queries about my appearance have sharpened such inner conundrums. These have intensified dilemmas about disclosure of my differences, prevarication of my body secrets and the ethics of reciprocal research relationships. Significant questions have 
surfaced for me around the costs of concealing or revealing my physical differences and attempts at body alteration and identity amendment, as well as the possible consequences of my silence or speech in carrying out research activities and in representing results.

One example of such questioning arose through an interview with Erum, a young South Asian Canadian woman. Like other participants in this study, Erum confronted increased pressures in the passage to womanhood to comply with dominant as well as South Asian diasporic cultural images of conventional female bodies to 'qualify' as womanly (Rice, 2003). My lines of inquiry traced effects on her sense of body, self and sexuality of social perceptions that sexualized and racialized pubertal changes in physical features such as breasts, weight and body hair. While many participants identified body hair as a problem trait, Erum emphasized how pubertal facial hair was especially frightening because it was read as a sign of biological maleness, visually undermining her sex and eliciting the scary feeling that she was not really a woman. She further implied that because it did not fit with certain diasporic and dominant images of 'good Indian girls', facial hair also violated prevailing ideas about proper appearance and sexual propriety of respectable South Asian girls. Echoing pubertal accounts of other Indo-Canadian contributors, she told how body hair breached notions of normative female bodies and conjured up ideas about racialized women as more hairy, masculine and asexual or inappropriately sexual, from within white- dominated culture:

In grade 8, I remember looking in the mirror and thinking 'Oh my god! Why are these hairs hanging out of my face? What if my friends see it and think I am so strange?' Good [Indian] girls don't have hair like that. I heard people making comments about the bearded lady ... After grade 9, it got to the point that even teachers would comment on it. One said, 'You have a lot of hair on your face. Why don't you get electrolysis done? Do you have hair on your breasts as well?'. . Even the doctor said: 'It is common for Indian girls to have hair on their face.' I know lots of Indian girls who don't have hair on their faces. Italian women are hairy too. So it's not true. It's a stereotyped generalization ... 
As Erum spoke about her fears of feeling 'other than female' because of hair, I identified deeply with her sense of difference. Like Erum, I have confronted cultural messages about the hairy female face and body as unfeminine, deviant and diseased. In a cultural context that restricts women's options for self-making, I, too, have concealed this rejected part to secure a credible gender identity and positive sense of self. I believe such experiential knowledge enabled me to more comfortably enter into conversation with her about the meanings and management of facial hair. When she revealed the ways that racialized women in west- ern culture are imagined as more hairy and masculine, I understood how this abject upholds a white ideal of femininity. Reflecting afterwards on her comment about Italian women, I realized that Erum was drawing from a cultural imaginary that saw Southern European women as dark/deviant others compared to light-skinned, hairless and hyper-feminine Northern European ideals. (Interestingly, although I am of both Scottish and Italian ancestry, others invariably have associated my hairiness with my Italianness, not my Scottishness!) I respected Erum's courage in revealing painful struggles, yet during our interview I found myself concealing similar experiences. In subsequent presentations to public and professional audiences, I continued to safeguard this secret. Over time, I have become uncomfortably aware of the ways that my secrecy, by contributing to cultural silence about white women's hairiness, also reinforces racialization of South Asian (and to a lesser extent, Southern European) women's bodies as other than feminine or female.

During another interview, Francis, a white woman in her mid-40s born with spina bifida, described the consequences of restrictive representations and confining spaces for her perceptions of bodily self. Like other women with disabilities, Francis traced social origins of her emotional distress to difficulties with being seen as a woman in a culture that distorts disabled women's gender and sexualities, and disqualifies their desirability and their desiring. Her description of mounting frustration as she moved through adolescence with widespread stereotypes of disabled bodies as unattractive and undesirable invited deeper exploration about the ways she was able to get through stressful adolescent years. To cope with anxiety and uncertainty about sexuality, identity and future directions, she created a rich fantasy life that 
centred on dreams of bodily transformation and of romantic love. Splitting her consciousness enabled her to shift between two bodily selves, one a received identity formed in response to others' negative perceptions, and the other, a 'best possible' bodily self she used to escape devaluation of her differences. Although daily misconceptions and marginalization compromised their identity choices, Francis's narrative under-scores the abilities of women with body differences in the context of everyday exclusions to preserve a sense of bodily self:

I had these great notions about having boyfriends and getting married. Yet a large part of me knew this wasn't going to happen. My mind just did this kind of separation thing . . . I needed to protect myself so I made up another reality. I never had an image of me that wasn't in the chair. But I would have images of me though looking different than I did in the sense that I would be much prettier, I would be slim. I would be popular.

When Francis spoke her outrage at a society that imposes certain body norms and ideals while ignoring physical abilities or possibilities unique to different bodies, I identified strongly with her anger. Like Francis, I have had to contend with cultural representations and social relations that have compromised my physical abilities and social identities by refusing to see female physical, social and sexual fitness as embodied in anything but a thin, white and able form (Rice, 2007). When she described how negative perceptions of disability disqualified her desirability, I related as well to the distress and defiance that inflected her response. I, too, recalled adolescent dreams of escaping otherness through bodily self- transformation and romantic love. Through her story, I came to see how my rage as a fat woman likewise was rooted in others' disqualification of my sexuality. (Some colleagues have subsequently revealed to me that they became interested in feminist disability scholarship precisely because of their similar adverse experiences as former fat girls.) Unlike Francis, however, I am acutely aware that my degree of body abjection has expanded and contracted with my size.

Significantly, when I conducted early interviews as a fat woman, participants 
with disabilities and differences tended to welcome my identification with their experiences as a way of breaking down rigid boundaries that exist in our society between the disabled and non-disabled worlds. By the time I interviewed Francis, however, I no longer embodied fatness. Due to disparities in our embodied experiences - her differences being visible and mine now unseen or amended - I felt that I no longer had an opening to disclose my history. Over time, I have realized that rather than conveying respect for this difference, my silence about our experiential affinities may have rendered her vulnerable to my 'normalized' gaze. This in turn may have worked to reinforce binary oppositions between 'normal' and 'anomalous' bodies that contribute to othering of many women living with bodily differences.

As I concealed my body secrets and the ways my embodied experiences intersected with participants' stories, I began to wonder how my secrecy might be shaping the project or shutting down important avenues of analysis. When my body shifted over the course of conducting interviews to a culturally acceptable size, I sensed that some women were intimidated or alienated by my appearance while others were drawn into intimate exchange because of the cultural power of beauty. Many revealed this range of responses with queries such as 'Why are you doing this research?' and 'What made you interested in this topic?' While initially I believed women posed personal questions primarily because they wanted more intimate information about my body issues, I gradually began to understand that they were asking for an ethical accounting more than a confessional recounting of my reasons for conducting the research. In my conversations with women marginalized by societal misconceptions about their bodies, some subtly wondered whether I had the insight needed to revision conventional accounts and enrich understanding about living with bodily differences. During these moments, Erum's and Francis's stories that called to mind my own abjection came back to haunt me. Their accounts, combined with some participants' speculations about my motives, raised troubling ethical questions about what seemed to me to be a profoundly inadequate response on my part to women's difficult disclosures - silence. I wondered whether disclosing my secrets would have enabled participants to tell their own; allowed us to enter into generative discussions about our experiential commonalities and differences; 
interrupted processes of othering; or merely re-centred my embodiment? I also realized that rather than superficial sharing of similar experiences, participants wanted deeper assurances about my ethical intentions in representing their stories.

Critical questions about my qualifications to responsibly analyse informants' accounts also were raised during public lectures about this research. For instance, after one talk, a young academic asked me how I could name so many bodily differences and affinities between myself and participants while ignoring what she perceived to be the 'elephant in the room': that I was 'an attractive woman'. At that moment, I realized the impossibility of removing my bodily struggles from interpretation. As I scrambled to compose a credible answer, I once again confronted my duplicity. Although my drive for self-protection trumped my desire to tell the truth, in that moment, the stresses of passing peaked. Reflecting on the queries that culminated with this young woman's question, I began a searching examination of my critical intentions, including my role in upholding or interrupting processes of 'othering' throughout the research (Wilkinson and Kitzinger, 1996). I began to appreciate the privileges of passing as a conventional woman: from the safe space of the unmarked centre, I could theorize about other/ed women's lives. This insight finally galvanized me to turn the gaze on myself.

Feminists have shown how academic research processes privilege the objective pursuit of knowledge devoid of emotions or bodily experiences, which are disregarded as irrational, overly subjective and ultra-feminine (Deutsch, 2004; Reger, 2001). As a result of internalizing dominant ideas about what counts as legitimate knowledge, I removed my emotions and embodied experiences from theorizing. When I buried my connections to participants' stories, I suppressed my embodied experiences as an important register for testing resonances of my interpretations, as well as a source of insight into theorizing women's psyches. For example, some feminists have argued that sexist, racist, ablest and consumerist interests push women into appearance alteration to satisfy culturally contoured desires, assuage collective fears about difference and cure their dissatisfactions created by these forces (Bordo, 1993). Others contend that women are not cultural dupes but 'secret 
agents' who rightly reject body otherness and strategically alter their appearance in their own best interests (Davis, 1995).

My own body secrets considered in conjunction with informants' accounts suggested to me that appearance alteration might encapsulate both feminist positions - that women's imagined or actual attempts at bodily transformation simultaneously may signify their capitulation to hegemonic ideals and opposition to harmful abjection. Within a social world intolerant of sexual ambiguity and physical difference, I realized that 'amending the abject' may be one of our few chances for social acceptance and emotional health (Covino, 2004). This does not mean those in this study either were constrained to fit cultural ideals or condemned to a life of misery. Rather, many suggest that they had two options in dealing with pervasive beauty ideals and disparagement of differences: changing their bodies (to the extent that they were ethically, technologically and/or financially able to); and/or changing their social locations (by accessing or creating spaces and relationships in which they found value and affirmation for their embodiments) (Rice, 2003). Most negotiated between both. At the same time, many participants note that changing locations was especially challenging from certain positions and during specific times such as such as adolescence when they had limited capacity to intervene in or alter important contexts of school and home.

Concealing my abject allowed me to escape the pain of being seen as other. But burying my bodily otherness also enabled me to avoid analysing how passing sustains oppressive ideals that ultimately perpetuate such pain. This became especially evident to me through stories told by participants who were not privileged to pass as conventional women. In this way, self-reflexivity permitted deeper exploration into dynamics of bodily privilege and abjection operating within the research. At the onset of the project, I aimed to centre women's subjectivities by decentring my own. In the wake of grappling with critical questions about embodied reflexivity, I have sought to counter-weigh cautious disclosure with another ethical aim: to be accountable for the ways that personal experiences have marked my interpretation of women's stories. My reflections on this issue have begun to suggest 
that analysis of body secrets may be necessary to theorize further power relations infusing this account.

\section{Theorizing Body Secrets}

Feminist methodologists have begun to consider how women's secrets carry knowledge imagined as dangerous to the social order that must be contained through censure, shame or other means of social control (Handa, 2003). While 'secret' suggests a private withholding of particularly charged information, for something to attain the status of secret rather than simply remain unknown, its existence must be shared (Gilbert, 2007). The secret implies and relies on a relationship between the keeper of secrets and others who may be aware of the existence of the secret but not necessarily share its contents. Thus, secrets conceal and reveal knowledge, and may be thought of as language strategies that people deploy to manage and make information known to selective audiences (White, 2000). As feminist historians and cultural theorists have shown, although women may or may not see themselves as actively keeping secrets, in the history of west- ern culture, they ubiquitously have been represented as secretive (Parkins, 2007). For example, western science since the early modern period has conceptualized women's genitalia and generational processes as the domain of secrets, which scientific tools have been harnessed to penetrate and police (Green, 2000). With the rise of consumer culture, commercial interests in fashion and cosmetics have continued to colonize and capitalize on women's apparent beauty secrets, which male purveyors have repackaged as products for expanding female markets. According to Parkins (2007), this cultural history suggests that framing know- ledge as a secret does not suppress as much as organize such knowledge along official and unofficial domains. Rather than restricting access to women's bodies, official representations of female bodies and beauty practices as secrets have rendered these open to greater patriarchal, professional and profit-making power. In addition, by relegating women's secret-keeping to the informal realm, this organization of knowledge has had serious consequences for their status as knowing subjects (Parkins, 2007).

Associations of secrets with the female have reinforced potent cultural myths 
of women as mysterious, enigmatic, covert and sly, which has mobilized the potential power of their supposed secrets to serve medical experts' and marketers' own ends. Relegation of women's body secrets to the private realm additionally serves to sustain and reproduce the hegemonic sex/gender system. Paradoxically, beauty secrets such as removal of body hair that uphold sex categories as 'natural' also serve to suppress knowledge about the ways sex differences are socially produced. In this research, my secrecy about physical differences reflects deep shame in not getting femininity 'right' naturally, recurring anxiety about not qualifying as a woman, as well as ongoing concern with masking modification of my abject parts. Because it represents capitulation to cultural images of conventional female bodies and rejection of bodily otherness, secrecy simultaneously signals my conformity and agency. While feminists theorize how women's silence and secrets are responses to oppression, they also examine ways that refusal of speech might reflect and reinforce speakers' positions of privilege (Mulvey et al., 2000). By concealing my physical differences, I benefit from psychological and social privileges associated with accomplishing conventional femininity as well as a normative female body. Secrecy further deflects perceptions that I am too conflicted to be a competent researcher in this area, which shores up my status as a disembodied expert. At the same time, masking physical differences has caused me significant stress over the years.

My own bodily abjection, a strong motivating force in initiating this project, increasingly has gone underground in carrying out the research. At the same time, recognizing participants' vulnerability and generosity in revealing intimate experiences has moved me to reconsider my affinities with their accounts. By theorizing from the first person, I have sought to revalue body secrecy as a sophisticated strategy for mediating the contradictory cultural requirement that women produce, yet conceal the production of, sex and gender. Through reconsidering my body secrets in relation to other women's actual or imagined body modification strategies, I additionally have aimed to reclaim women's status as knowing subjects in navigating beauty ideals and body norms. In the next section, I reflect on strategies of 'embodied engagement' I deployed to deal with challenges my body secrets presented in an attempt to do research differently. 


\section{METHODOLOGICAL CHALLENGES OF EMBODIED ENGAGEMENT}

Throughout this project, informant, audience and feminist methodological queries sparked an ongoing examination of the ways my body history and changing embodiments were influencing research activities. I came to identify this form of reflexivity as 'embodied engagement'. For example, in the interview phase of this project, I recorded participants' responses to my appearance and noted how their reactions often receded into the background once I demonstrated my commitment to understanding differences and succeeded in joining with them to uncover intensities and complexities of their accounts. Still, I sensed ways that cultural power operating through our appearances and differences continued to haunt the interviews. While I aimed for reciprocal relationships (Bloom, 1998), I discovered many interviewees did not want to engage in dialogic exchange. During some interactions, I sensed that my telling of relevant anecdotes temporarily ruptured our developing rapport, placing burden on participants to respond to my disclosure and disrupting our focus on their story telling. I realized that western interviewing conventions would predispose many participants to see researchers primarily as objective observers. I also began to believe that participants' responses were partially rooted in their understanding about ways our culture values the images and voices of women viewed as attractive while devaluing those seen as different. Much to my chagrin, my attempts at reciprocal story- telling often reinforced inequities based on appearance more than they increased openings for equitable exchanges across differences. With this realization, I wondered how I was going to navigate encounters without resorting to personal disclosure or professional detachment that reproduced my positions of bodily privilege.

Little by little, I found ways to approach the problem of power posed by physical difference. I learned to establish my presence by conveying that I was informed about certain issues but interested in understanding, and in centring, informants' insights. By reading widely about experiences of women with disabilities and differences, racialized women and those perceived as overweight within a visual culture dominated by images of fit, flawless bodies, I composed questions that spoke to the 
specificity of contributors' experiences. For example, the questions: 'When and how did you become aware of having a disability and/or physical difference?' and 'What, if anything, did you learn about your body in medical systems?' enabled Francis and others with disabilities to consider the effects of early aversive experiences in medical and segregated school systems on their perceptions of bodily self. I was resolved through my use of questions and body language (such as by leaning forward, maintaining eye contact and using facial expressions to show I was following the emotional-intellectual contents of their accounts) to create a relational space in which racialized women and those living with disabilities and size differences could comfortably and safely reveal and reflect on differences. By adopting a stance of 'embodied engagement' that acknowledged my positions (either to interviewees or myself) while privileging participants' perspectives, I could convey an openness to explore unique and common aspects of experiences, which facilitated discovery of new knowledges about bodily selves. Importantly, through centring the specificity of each woman's story while bearing in mind my points of connection with her account, I crafted new questions that invited consideration of commonalities across differences. Emergent queries such as 'When, if ever, did you begin to feel like a woman?' and 'To what extent do you feel like a woman in your daily life?' enabled Francis, Erum and others to reflect on 'qualifying' as a woman and/or to consider when and how perceptions of differences have disqualified them. In this way, embodied engagement allowed me to balance self-revelation and reflection with an intention to centre informants' insights in interpreting their lives.

\section{Decentring My Bodily Self}

Researchers informed by post-conventional perspectives confront contradictions of theorizing differences emerging in research relationships while placing participants' subjectivities and circumstances at the centre of analysis. For researchers from positions of bodily privilege, issues of interviewing and interpretation intensify when researching across physical differences distorted by oppressive cultural representations and social relations. In this study, social differences between participants and myself made some body-related topics - including issues of colourism and racism, adverse treatment in medical systems and histories of sexual 
abuse - difficult to discuss and even to raise. As I conducted interviews, I became practised at gesturing towards topics that facilitated women's descriptions and disclosures while respecting their comfort levels in telling of experiences. Key to this process was posing evocative questions that facilitated close exploration of sensitive subjects without making assumptions about visible or invisible differences. For example, I found that the question 'What is an early or perhaps your earliest memories of your body?' called to mind for some women memories of sexual abuse, and its consequences for embodiment and identity. For many others, this probe elicited early accounts of physical spontaneity or 'spontaneous bodies' where regardless of the presence or absence of a disability or difference, women experienced their bodies as playful vehicles for active exploration of the world. The queries 'Did you ever look at your reflection and think you were different from other kids?' and 'How did you get this message?' evoked recollections about effects of racialization, disablism or sizism on their sense of bodily self. In this way, questions generated insights about implications of bodily perceptions for self-making without implying judgments about meanings, effects or ethics of experiences.

I endeavoured to accept and analyse differences made audible in interviews through not reacting defensively to women's interpretations or relating their stories back to my own (Deutsch, 2004). The more I used the narrative strategy of decentring myself - by simultaneously striving to put myself in their place and to grasp how my positionality might impede my listening, learning and understanding - the more participants could speak openly and direct the focus according to their understandings and interests. Thus, 'de-centring' enabled me to focus the inquiry on unique aspects of each woman's story while drawing from my own and other women's points of difference and affinity with her account in formulating follow up questions. Increasingly, I was able to evoke experiences of those previously interviewed. I began to speak not only to the woman in the room, but with and about all interviewees in an exchange that acknowledged differences and affinities between and among participants and myself. For example, in my interview with Erum, I told how other South Asian Canadian participants had identified body hair as a problem trait. Rather than naturalize associations between race and hair, I phrased my questions in a way 
that reframed this finding: 'Why do you think white people like your doctor say hurtful things like "Indian girls are hairy?"' In this way, questions and comments that recognized differences and commonalities in experiences enabled Erum and others to tell their stories, and allowed us to explore broader themes such as why IndoCanadian women were perceived as more hairy within white-dominated contexts.

\section{Revisiting my Story}

At the onset of this project, I was anxious to avoid interpretive approaches that violated women's sense of themselves or appropriated their stories to tell my own. I found that conducting a self-interview allowed me to contribute to participants' chorus of voices without taking a principal part. To evaluate my open-ended interview schedule, I asked a colleague with expertise in body image to use this guide in interviewing me about my reflections and revelations on past and present bodily experiences. I then transcribed and filed away the interview for future review. After spending a year immersed in other women's stories, I was shocked to discover upon returning to my own that I had become an 'other' to myself. When I re-read my transcript, I encountered a familiar yet foreign self who I recognized but no longer regarded as me. It was difficult to stay present with the pain and anger that made her story simmer. For the first time, I understood how narratives captured ephemeral moments in individuals' lives. Surprised by the forceful emotions that gripped me when I encountered this other who had been displaced by subsequent selves, I inferred that some participants might have similar responses to their stories. As a result, I resolved to cultivate appreciation for the intensities, vulnerabilities, strengths and mutability these (both my own and others') former selves revealed. I began to view interpretation as a 'relational process' that occurred between investigator and informants as well as between researcher and participants' past and present selves. A relational approach enabled me to stay 'emotionally attuned' with experiences women revealed while I imagined their responses to my provisional theory building (Hoskins and Stoltz, 2005).

I came to understand how my embodiment at the time of the self-interview (when I was a fat woman) had significantly affected my intellectual and emotional 
investments, and contoured my interpretation of experiences told. Taking a critical approach to interpretation allowed me to make multiple meanings of my body history, by enabling me to see how my interpretations shifted and changed along with my subjectivity at different times because of differing embodiments. The rage I had felt because of others' rejection of my body gradually decreased along with my diminishing weight, but reconnecting with this 'other within' helped me to relate to strong emotions that inflected women's responses. Through appreciating the intensity, vulnerability, fluidity and dissimilarity to my present bodily self that revisiting this previous embodiment revealed, I could begin to acknowledge the unbridgeable space between self and other, and other in the self. While they frightened me, I came to see how re-encountering these abject images that now haunted me could bring me closer to imagining others' accounts.

\section{Imagining Others' Embodied Experiences}

Many feminists have been moved by Sandra Harding's call for researchers to 'reinvent' themselves as other as a way to begin thinking from diverse women's lives (Harding, 1991; McCorkel and Myers, 2003). Because her approach implies that researchers should strive to occupy participants' vantage points, it can be interpreted as a colonizing stance. At the same time, feminists argue that women can and do traverse differences to look for affinities without assuming an arrogant universalizing role as a strategy for revisioning differences when received identities do not serve their interests (Yuval-Davis and Stoeltzler, 2002). To foster dialogic exchange, YuvalDavis (1997) proposes a transversal approach that combines 'rooting' in one's own situation (understanding one's position, history, and implicatedness in current conditions) with 'shifting' to the position of the other (understanding historical and contemporary relations and conditions from the other's perspective) as a method for developing difference-sensitive feminism. According to Yuval-Davis (1997), a traversal politics replaces feminist claims or aims of unity and sameness with dialogues that recognize women's situated differences and strive to find or forge common values from divergent positions. While feminists since have advocated taking a transversal approach for crossing borders of ethnicity, nationality, positionality and place (Archer, 2004), such a method also could be used by those seeking to traverse boundaries of 
body and physical space.

One way in which shifting between differing positions may take place is by creative processes of imagining others' embodied existences. This approach echoes the insights of Toni Morrison who, reflecting on writers' ability to project themselves into others, writes, 'imagining is not merely looking or looking at; nor is it taking one's self intact into the other. It is, for the purposes of the work, becoming' (1992: 4). While Morrison is describing the process of writing about difference in fiction, this description equally explains the engagement in this study of participants' imaginations with the cultural imaginary in their body image, identity and self-making. Echoing participants' generative engagement with 'becoming', Morrison's description also captures my own imaginative engagement with their stories. Only after countless hours spent rapt in their chronicles did I realize that 'imagining becoming the other' was critical to my interpretive approach.

While the rootedness of the writer's or researcher's gaze undeniably contours the horizons of her imagination (Stoetzler and Yuval Davis, 2000), I envisaged Morrison's method of imagining as one that avoided the usual pitfalls of approaching differences. It did not involve an appropriating stance of becoming the other, in which writers and researchers cast off their values, investments or implicatedness to fantasize merging with a mythical other. Nor did it mean a distancing stance implied by imagining the other, wherein writers cast their own experiences, perceptions, emotions and selves, intact and untouched, into an emptied-out other. I came to see imagining becoming the other as a stance that acknowledged the space between self and other, that approached rather than appropriated others' experiences, and that invited generative engagement with, over denial of, or disengagement from, differences. Through revisiting my own body history, I tried to imagine inhabiting others' bodies while I considered their possible responses to my imaginings. In Erum's case, this meant taking seriously her assertion that hair removal represented an attempt to escape body otherness. In analysing Francis's story, I considered that her fantasies involved more than capitulation to cultural values but represented a strategy to survive alienating adolescent years. Central to a transversal approach was 
shifting between empathically interpreting my own body history and empathically imagining others' embodied lives. Significantly, this method enabled me to recognize differences and affinities while respecting indeterminacy of my own and other women's accounts.

I used empathic imagining as a way to risk feeling and fathoming while resisting mastery over other women's experiences. In the wake of completing this work, however, I am left with an unsettling question regarding the perils of traversing the space between self and other in feminist-informed research. I worry about 'playing in the dark', to extend Toni Morrison's metaphor (about the ways that white writers historically have projected their culturally shaped anxieties and desires onto the racialized characters they create) beyond the literary to the researcher's imagination, about how my 'imaginative leap' into other women's lives might embody my own fears and desires. Methods of de-centring myself, revisiting my body story and imagining becoming the other have made possible more faithful accounts that come closer to informants' experiences. However, dilemmas of power and difference remain. I hope that the narratives resonate with participants and with other women. Yet I recognize that my interpretations may be as much about my relationship to informants' accounts as about the relationship of the women who narrated them to the circumstances in which they live.

\section{CONCLUSION}

Women's body histories indicate that appearance and difference have become major markers of identity for girls growing up in image culture. Appearance has joined sex, disability and race as a powerful visual symbol of distinguished or devalued difference that variously shapes and constrains women's sense of identity and possibility as they make their way in our 'body-centric' world. While researcher selfreflexivity is now acknowledged as a key component of critical research, what receives less attention is how the politics of physical appearance and difference might play out in research or other social relations (Burns, 2006). Feminist investigators have explored influences of identities such as race, class, gender, age, ability and nation on researchers' interactions with respondents and on the integrity of 
knowledge they produce. Many have found the salience of social categories to be more complex, subtle and unstable than scholars previously have acknowledged (Ghorashi, 2005; Johnson-Bailey, 1999). Throughout this study, my experiences of abjection resonated with women's accounts in ways that were not necessarily visible or apparent through the lens of race, disability and other conventional categories familiar to feminists. My appearance as well as overt and covert differences took on as much importance as other positions of privilege or oppression in interviews and interpretations, emerging as the most visible and invisible, variable, contentious and salient aspects of my identity and positionality. Significantly, such an insight may point to the importance of not retreating to familiar axes of power and oppression (race, class and gender) as primary interpretive lens when researching women's embodiments.

Ethical challenges of researching women's body histories illustrate the pivotal part played by researchers' embodied subjectivities in knowledge production. This inquiry, in particular, has considered how one researcher's positionality, personal history and physicality have contoured the content and interpretation of interviews. Women's narratives that called to mind my own body struggles caused intense inner conflict, confusion and questioning that brought me face to face with the other in myself. Encountering this 'other within' has emerged as the most theoretically rich part of the research process. Whether fat, facial hair or another rejected attribute, women's accounts speak powerfully to how the phantom of the abject part that haunts the self can become an other to that self. These stories evoke the spectre of the woman who suppresses the bodily other 'within' in an effort to escape her designation as deviant. My analysis of body secrets further reveals how researchers may be called to confront the phantoms of their own physical differences when striving to conduct ethical research on embodiment.

Embodied reflexivity reveals how the rich body histories of researchers, as well as participants, contour research. Had I not conducted a self-interview, analysed the effects of my body secrets or adopted strategies of embodied engagement, I might have become mired in feminist debates about beauty practices, ignored women's 
covert agency or missed how body modification simultaneously can encapsulate their subjugation and survival. More broadly, I might have missed how physical appearance surfaced in this study as a critically important analytic category that intersected and overlapped with, but was irreducible to, more familiar social categories. Through analysing body privilege and abjection underpinning research processes, feminist researchers can contribute to theorizing how physical differences constitute embodied subjectivities and new positionalities within visual culture as well as shape women's image struggles and resulting strategies for body modification. Few feminist researchers have focused on power relations operating through physical differences in women's relation- ships. Yet attending to these would offer valuable insights into social relations of appearance and difference that regulate our daily lives.

\section{ACKNOWLEDGEMENTS}

I want to thank the women who generously agreed to participate in this project, especially Erum and Francis, from whom I have learned so much. I also wish to acknowledge and thank my mentors Lorraine Code, Nancy Mandell, and Virginia Rock, my colleagues Virginia Braun, Claire Carter, Fatima Correia, Susan Dion, Eva Karpinski, Jennifer Nelson, and Lorna Renooy, and the anonymous reviewers and audience members whose perceptive comments have contributed significantly to strengthening ideas developed in this article. Many thanks are extended to llya Parkins for introducing me to the rich feminist writing on secrets.

\section{REFERENCES}

Archer, L. (2004) 'Re/theorizing "Difference" in Feminist Research', Women's Studies International Forum 27(5-6): 459-73.

Bloom, L. (1998) Under the Sign of Hope: Feminist Methodology and Narrative Interpretation. Albany, NY: State University of New York Press.

Bordo, S. (1993) Unbearable Weight: Feminism, Western Culture and the Body. Los Angeles, CA: University of California Press.

Brah, A. (2001) ‘Difference, Diversity, Differentiation’, in K. Bhavnani (ed.) Feminism 
and 'Race', pp. 456-78. New York: Oxford University Press.

Burns, M. (2006) 'Bodies that Speak: Examining the Dialogues in Research Interactions', Qualitative Research in Psychology 3(1): 3-18.

Canadian Research Institute for the Advancement of Women (CRIAW) (1996) Feminist Research Ethics: A Process. Ottawa, ON, Canada: CRIAW.

Clandinin, J. and Connelly, M. (2000) Narrative Inquiry: Experience and Story in Qualitative Research. San Francisco, CA: Jossey-Bass.

Cosgrove, L. and McHugh, M. (2000) 'Speaking for Ourselves: Feminist Methods and Community Psychology', American Journal of Community Psychology 28(6): 815-38.

Covino D. (2004) Amending the Abject Body: Aesthetic Makeovers in Medicine and Culture. Albany, NY: State University of New York Press.

Davis, K. (1995) Reshaping the Female Body: The Dilemma of Cosmetic Surgery. New York: Routledge.

Deutsch, N.L. (2004) 'Positionality and the Pen: Reflections on the Process of Becoming a Feminist Researcher and Writer', Qualitative Inquiry 10(6): 885902.

Fine, M., Weis L., Weseen, S. and Wong, L. (2003) 'For Whom? Qualitative Research, Representations, and Social Responsibilities', in N. Denzin and Y. Lincoln (eds) The Landscape of Qualitative Research: Theories and Issues (2nd edition) pp. 167-207. Thousand Oaks, CA: Sage.

Fonow, M. and Cook, J. (2005) 'Feminist Methodology: New Applications in the Academy and Public Policy', Signs: Journal of Women in Culture \& Society 30(4): 2211-36.

Gilbert, J. (2007) 'Public Secrets: 'Being-with in an Era of Perpetual Disclosure', 
Cultural Studies 21(1): 22-41.

Ghorashi, H. (2005) 'When the Boundaries are Blurred: The Significance of Feminist Methods in Research', European Journal of Women's Studies 12(3): 363-75.

Green, M. (2000) 'From "Diseases of Women" to "Secrets of Women”: The Transforma- tion of Gynecological Literature in the Later Middle Ages', Journal of Medieval and Early Modern Studies 30(1): 5-38.

Grosz, E. (1994) Volatile Bodies: Toward a Corporeal Feminism. Bloomington, IN: Indiana University Press.

Handa, A. (2003) Of Silk Saris and Mini-Skirts: South Asian Girls Walk the Tightrope of Culture. Toronto: Women's Press.

Harding, S. (1991) Whose Science? Whose Knowledge? Thinking From Women's Lives. Ithaca, NY: Cornell University Press.

Henry, M. (2003) "'Where Are You Really From?" Representation, Identity and Power in the Fieldwork Experiences of a South Asian Diasporic', Qualitative Research 3(2): 229-42.

Hoskins, M. and Stoltz, J. (2005) 'Fear of Offending: Disclosing Researcher Discomfort when Engaging in Analysis', Qualitative Research 5(1): 95-111.

Johnson-Bailey, J. (1999) 'The Ties That Bind and the Shackles that Separate: Race, Gender, Class, and Color in a Research Process', International Journal of Qualitative Studies in Education 12(6), 659-70.

Kristeva, J. (1982) Powers of Horror: An Essay on Abjection, trans Leon Roudiez. New York: Columbia University Press.

Luttrell, W. (2000) '“Good Enough" Methods for Ethnographic Research', Harvard Educational Review 70(4): 499-523. 
Mama, A. (1995) Beyond the Masks: Race, Gender and Subjectivity. London: Routledge.

McCorkel, J. and Myers, K. (2003) 'What Difference Does Difference Make? Position and Privilege in the Field', Qualitative Sociology 26(2): 199-231.

Merrick, E. (1999) “'Like Chewing Gravel”: On the Experience of Analyzing Qualitative Research Findings Using a Feminist Epistemology', Psychology of Women Quarterly 23(1): 47-57.

Morrison, T. (1992) Playing in the Dark: Whiteness and the Literary Imagination. New York: Vintage Books.

Mulvey, A., Terenzio, M., Hill, J., Bond, M., Huygens, I., Hamerton, H. and Cahill, S. (2000) 'Stories of Relative Privilege: Power and Social Change in Feminist Community Psychology', American Journal of Community Psychology 28(6): 883911.

Naples, N. (2003) Feminism and Method: Ethnography, Discourse Analysis, and Activist Research. New York: Routledge.

Oakley, A. (1981) 'Interviewing Women: A Contradiction in Terms', in H. Roberts (ed.) Doing Feminist Research, pp. 30-61. London: Routledge.

Parkins, I (2007) 'Beauty Secrets: Women, Fashion, and Hidden Knowledges in Modernity', paper presented at the Canadian Women's Studies Association Conference, May, University of Saskatchewan, Saskatoon, Saskatchewan.

Reger, J. (2001) 'Emotions, Objectivity and Voice: An Analysis of a "Failed" Participant Observation', Women's Studies International Forum 24(5): 605-16.

Reissman, C. and Quinney, L. (2005) 'Narrative in Social Work: A Critical Review', Qualitative Social Work 4(4): 391-12.

Rice, C. (2003) 'Becoming Women: Body Image, Identity, and Difference in the 
Passage to Womanhood', unpublished Women's Studies Doctoral Dissertation, York University, Toronto.

Rice, C. (2007) 'Becoming "the Fat Girl”: Acquisition of an Unfit Identity', Women's Studies International Forum 30(2): 158-74.

Shildrick, M. (1997) Leaky Bodies and Boundaries: Feminism, Postmodernism, and (Bio)ethics. New York: Routledge.

Stoetzler, M. and Yuval-Davis, N. (2002) 'Standpoint theory, Situated Knowledge and the Situated Imagination', Feminist Theory 3(3): 315-33.

Strauss, A. and Corbin, J. (1998) Basics of Qualitative Research: Techniques and Procedures for Developing Grounded Theory. Thousand Oaks, CA: Sage.

Tuhiwai Smith, L. (1999) Decolonizing Methodologies: Research and Indigenous Peoples. London: Zed Books.

Weiss, G. (1999) Body Images: Embodiment as Intercorporeality. New York: Routledge.

White, L. (2000) 'Telling More: Lies, Secrets, and History', History and Theory 39(4): $11-22$.

Wilkinson, S. and Kitzinger, C. (eds) (1996) Representing the Other: A Feminism \& Psychology Reader. London: Sage.

Wolf, D. (ed.). (1996) Feminist Dilemmas in Fieldwork. Boulder, CO: Westview Press.

Yuval-Davis, N. (1997) Gender and Nation. London: Sage.

Yuval-Davis, N. and Stoetzler, M. (2002) 'Imagined Boundaries and Borders: A Gendered Gaze', European Journal of Women's Studies 9(3): 329-44.

Zitzelsberger, H. (2005) '(In)visibility: Accounts of Embodiment of Women with Physical Disability and Differences', Disability \& Society 20(4): 389-403. 